\title{
Identifying the risk factors of antepartum haemorrhage and to evaluate the feto maternal outcome in antepartum haemorrhage cases
}

\author{
Reeta Singh, Vani Aditya, Sakshi Agarwal, Garima Maurya*, \\ Ankita Kumari, Neela Rai Sharma
}

Department of Obstetrics and Gynaecology, BRD Medical College, Gorakhpur, Uttar Pradesh, India

Received: 03 September 2021

Revised: 20 September 2021

Accepted: 21 September 2021

\author{
*Correspondence: \\ Dr. Garima Maurya, \\ E-mail: maurya29121986@gmail.com
}

Copyright: (c) the author(s), publisher and licensee Medip Academy. This is an open-access article distributed under the terms of the Creative Commons Attribution Non-Commercial License, which permits unrestricted non-commercial use, distribution, and reproduction in any medium, provided the original work is properly cited.

\begin{abstract}
Background: Antepartum haemorrhage is an obstetric emergency contributing to a significant percentage of perinatal and maternal morbidity and mortality. Approximately $30 \%$ of maternal deaths are caused by ante-partum haemorrhage. In spite of a lot of improvement in antenatal care and intrapartum surveillance, antepar-tum haemorrhage has not reduced. Present study was conducted to assess the causes of APH and to compare the fetomaternal outcome among placenta previa and abruptio placenta group.

Methods: The study was conducted in BRD medical college Gorakhpur, over a period of 1 year (October 2019 to September 2020) in which 100 cases of APH were taken and classified into placenta previa and abruptio placenta group and their fetomaternal outcome were compared.

Results: In our study, out of 100 cases of APH $69 \%$ cases were of placenta previa followed by abruptio placen-ta in $29 \%$ cases and rest $2 \%$ cases were unclassified APH. Multigravida is the major risk factor in both placenta previa and abruptio placenta group. Second major risk factor in placenta previa group was h/o LSCS and in abruptio placenta group was HDP. Stillbirth was significantly seen in abruptio placenta group whereas Low birth weight babies $(1.5-2.5 \mathrm{~kg})$ were more in placenta previa group. Though the maternal outcome is poor in placenta previa group but the fetal outcome is worse in abruptio placenta group.

Conclusions: APH neither can be reliably predicted nor can be prevented but only a comprehensive focused experienced team work can reduce maternal and perinatal morbidity and mortality.
\end{abstract}

Keywords: APH, Antepartum haemorrhage, Perinatal morbidity

\section{INTRODUCTION}

Antepartum haemorrhage is defined as bleeding from or into the genital tract after 28 weeks of gestation or after the period of viability but before the birth of baby. ${ }^{1}$ It complicates $2-5 \%$ of all pregnancies. $^{2}$ Antepartum haemorrhage is an obstetric emergency contributing to a significant percentage of perinatal and maternal mor-bidity and mortality. Incidence of placenta previa at delivery is 1 in 200 births and incidence of abruption pla-centa is about 1 in 80 to 1 in 250 deliveries. ${ }^{3,4}$ Approximately $30 \%$ of maternal deaths are caused by antepar-tum haemorrhage. In spite of a lot of improvement in antenatal care and intrapartum surveillance, antepartum haemorrhage has not reduced. ${ }^{5}$

Causes of APH is divided in 3 categories:

Placenta previa: When placenta is implanted partially or whole in lower segment of the utérus.

Abruption placenta: When bleeding occurs due to premature separation of normal situated placenta. 
Unclassified: Marginal sinus rupture, cervicitis, trauma, genital cancer, local lesions of cervix and vagina, Vasa previa.

Placenta previa and abruption placenta accounts for almost half of cases of APH. ${ }^{6}$ Maternal complica-tions of APH includes preterm delivery, post partum haemorrhage, retained placenta, morbidly adherent placenta, anaemia, hypovolemic shock, acute renal failure, increasing rate of caesarean section, puerperal sepsis, peripartum hysterectomy, maternal mortality and risk of recurrence. Fetal complication includes preterm delivery, low birth weight, fetal growth restriction, congenital malformation, IUD and birth asphyxia. ${ }^{7}$

In developing country like India, women frequently experiencing the adverse effect of obstetric haemor-rhage due to pre-existing anaemia, delay in referral, poor accessibility and overwhelming inadequacies of maternity services. 8

\section{Aims and objective of study}

To know the causes of antepartum haemorrhage. To know the risk factors for placenta previa and abruption placenta. To compare the fetomaternal outcome in patients of placenta previa and abruption placenta.

\section{METHODS}

\section{Study type}

The study design was prospective.

\section{Study place}

The study was conducted at Department of Obstetrics and Gynaecology, BRD Medical College Gorakhpur, Uttar Pradesh.

\section{Study period}

The study was conducted for a period of 1 year (1 October 2019 to 30 September 2020).

\section{Selection criteria}

100 antenatal women with the diagnosis of APH were included in our study. Patients with bleeding before 28 weeks and after the delivery of baby were excluded from the study.

\section{Procedure of the study}

All antenatal women who came to attend OPD or emergency room with APH were screen by history and per abdominal and per speculum examination. In case of emergency first resuscitation of patient was done. Then ultrasonography was done to rule out placenta previa and after excluding it per vaginal examination done. After making the diagnosis cases were classified those who give the consent and met the inclusion criteria were included in our study. Cases were followed till delivery and their maternal and fetal outcomes were noted.

Statistical analysis were done by using charts and tables and chi square test was applied.

\section{Ethical approval}

Ethical approval was obtained from institution for the study.

\section{RESULTS}

During the 1 year study period 100 cases of antepartum haemorrhage were enrolled for the study.

Table 1: Causes of APH.

\begin{tabular}{|lll|}
\hline Causes of APH & Total cases $(\mathbf{n}=\mathbf{1 0 0})$ & $\%$ \\
\hline Placenta previa & 69 & 69 \\
\hline $\begin{array}{l}\text { Placenta } \\
\text { abruption }\end{array}$ & 29 & 29 \\
\hline Unclassified & 2 & 2 \\
\hline
\end{tabular}

Table 2: Sociodemographic profile.

\begin{tabular}{|llll|}
\hline \multirow{2}{*}{ Parameters } & & $\begin{array}{l}\text { Number } \\
(\mathbf{1 0 0})\end{array}$ & \% \\
\hline \multirow{4}{*}{ Dwe } & <30 years & 86 & 86 \\
\hline & $>30$ years & 14 & 14 \\
\hline \multirow{4}{*}{ Education } & Rural & 74 & 74 \\
\hline \multirow{5}{*}{$\begin{array}{l}\text { SES } \\
\text { (Kuppuswamy) }\end{array}$} & Urban & 26 & 26 \\
\cline { 2 - 4 } & Illiterate & 38 & 38 \\
\cline { 2 - 4 } & Primary & 10 & 10 \\
\cline { 2 - 4 } & school & 13 & 13 \\
\cline { 2 - 4 } & Jr high school & 13 & 21 \\
\cline { 2 - 4 } & High school & 21 & 15 \\
\cline { 2 - 4 } & Intermediate & 15 & 3 \\
\cline { 2 - 4 } & Graduate & 3 & 4 \\
\cline { 2 - 4 } & Upper & 0 & 40 \\
\cline { 2 - 4 } & Upper middle & 4 & 4 \\
\hline
\end{tabular}

Table 1 shows causes of APH, $69 \%$ patients had placenta previa while $29 \%$ had abruption placenta and $2 \%$ patients had unclassified APH.

Table 2 shows the sociodemographic profile of APH cases, among the all cases of APH $86 \%$ patients were be-low 30 years and only $14 \%$ patients were more than 30 years.

$74 \%$ cases of APH belonged to rural area and $26 \%$ belonged to urban area. 
Table 3: Complains of APH.

\begin{tabular}{|lll|}
\hline Complains & $\begin{array}{l}\text { No. of } \\
\text { cases }\end{array}$ & $\%$ \\
\hline $\begin{array}{l}\text { Painless bleeding per } \\
\text { vaginum }\end{array}$ & 70 & 70 \\
\hline $\begin{array}{l}\text { Painful bleeding per } \\
\text { vaginum }\end{array}$ & 13 & 13 \\
\hline $\begin{array}{l}\text { Headache, blurring of } \\
\text { vision, epigastric pain }\end{array}$ & 15 & 15 \\
\hline Convulsion & 1 & 1 \\
\hline $\begin{array}{l}\text { watery discharge per } \\
\text { vaginum }\end{array}$ & 1 & 1 \\
\hline
\end{tabular}

Table 4: Risk factors of APH.

\begin{tabular}{|lll|}
\hline Risk factor of APH & $\begin{array}{l}\text { No. of } \\
\text { cases }\end{array}$ & $\%$ \\
\hline Multigravida & 86 & 86 \\
\hline History of LSCS & 30 & 30 \\
\hline History of Abortion & 23 & 23 \\
\hline History of D\&E & 13 & 13 \\
\hline History of PID & 12 & 12 \\
\hline Endometriosis & 10 & 10 \\
\hline History of MRP & 5 & 5 \\
\hline $\begin{array}{l}\text { History of infertility } \\
\text { treatment }\end{array}$ & 4 & 4 \\
\hline Multiple pregnancy & 3 & 3 \\
\hline $\begin{array}{l}\text { History of Puerperal } \\
\text { sepsis }\end{array}$ & 3 & 3 \\
\hline
\end{tabular}

Table 5: Risk factors for placenta previa $(\mathrm{N}=69)$.

\begin{tabular}{|lll|}
\hline Risk factor & Number & $\%$ \\
\hline Multigravida & 62 & 89.8 \\
\hline History of LSCS & 22 & 32 \\
\hline History of PPH & 10 & 14.5 \\
\hline History of abortion & 6 & 8.6 \\
\hline History of D and E & 5 & 7.2 \\
\hline $\begin{array}{l}\text { History of manual } \\
\text { removal of placenta } \\
\text { (MRP) }\end{array}$ & 5 & 7.2 \\
\hline $\begin{array}{l}\text { ART (Assisted } \\
\text { reproductive treatment) }\end{array}$ & 3 & 4.3 \\
\hline Multiple pregnancy & 3 & 4.3 \\
\hline Rh negative pregnancy & 4 & 5.7 \\
\hline $\begin{array}{l}\text { History of puerperal } \\
\text { sepsis }\end{array}$ & 1 & 1.4 \\
\hline
\end{tabular}

$38 \%$ women were illiterate, $21 \%$ women were educated upto high school and $3 \%$ were graduated.

According to Kuppuswamy classification of socioeconomic status $40 \%$ (maximum) antenatal women were belonged to lower class, $35 \%$ cases were belonged to upper lower class followed by $21 \%$ cases belonged to lower middle class and $4 \%$ belonged to upper middle class.
Table 6: Risk factors for abruption placenta $(n=29)$.

\begin{tabular}{|lll|}
\hline Risk factors & $\begin{array}{l}\text { No. of } \\
\text { cases }\end{array}$ & $\%$ \\
\hline Multigravida & 22 & 75.8 \\
\hline $\begin{array}{l}\text { HDP (Hypertensive } \\
\text { disorder of pregnancy) }\end{array}$ & 15 & 51.72 \\
\hline Short cord & 1 & 3.14 \\
\hline $\begin{array}{l}\text { Placental abnormality } \\
\text { (Battledore placenta) }\end{array}$ & 2 & 6.8 \\
\hline PPROM & 1 & 3.14 \\
\hline Trauma & 1 & 3.14 \\
\hline Hypothyroidism & 3 & 10.3 \\
\hline Hyperthyroidism & 1 & 3.14 \\
\hline
\end{tabular}

Table 3 shows complains of APH, 70\% cases presented with painless bleeding, $13 \%$ patients presented with painful bleeding, $15 \%$ cases presented with features of preeclampsia, $1 \%$ patient had complain of watery dis-charge and $1 \%$ patient presented with convulsion.

Table 4 shows risk factors for APH, out of 100 APH cases, $86 \%$ cases were multigravida, $30 \%$ cases had histo-ry of LSCS, $23 \%$ cases had history of abortion, $12 \%$ cases had history of PID, $10 \%$ cases had history of endo-metriosis, $4 \%$ patients took treatment for infertility, $13 \%$ cases had history of D and E, 5\% cases had history of MRP, $3 \%$ cases had history of puerperal sepsis, $3 \%$ cases had multiple fetus in present pregnancy.

Table 5 shows the risk factors associated with placenta previa, $89.8 \%$ cases were multigravida, $32 \%$ cases had history of LSCS, $14.5 \%$ patients had history of PPH, $7.2 \%$ had history of D and E and MRP, $5.7 \%$ cases were Rhnegative pregnancy followed by ART and Multiple pregnancy in $4.3 \%$ cases and $1.4 \%$ cases had history of puerperal sepsis.

Table 6 shows the risk factors of abruptio placenta,75.8\% cases of abruption placenta were multigravida, HDP was present in $51.72 \%$ cases of abruptio placenta, hypothyroidism was seen in $10.3 \%$ of cases, $9.9 \%$ cases were associated with placental abnormality, PPROM hyperthyroidism and trauma was present in $3.14 \%$ of cases.

Significantly more patients in placenta previa group had underwent cesarean section and had blood transfusion compared to abruptio placenta group ( $\mathrm{p}$ values is 0.00 and 0.003 respectively). Couvalaire uterus is significant-ly seen in abruptio placenta group $(\mathrm{p}=0.00)$. $\mathrm{PPH}$, scar dehiscence and ICU admission is comparable in both the groups.

Stillbirth is significantly seen in abruptio placenta group whereas Low birth weight babies $(1.5-2.5 \mathrm{~kg})$ were more in placenta previa group. 
Neonatal death were higher in placenta previa group than abruption placenta although it is statistically not significant. NICU admission and gestational age at the time of delivery is comparable in both the group.

Table 7: Maternal outcome of placenta previa and abruption placenta.

\begin{tabular}{|llll|}
\hline Maternal outcome & $\begin{array}{l}\text { Placenta previa } \\
(\mathbf{n = 6 9 )}(\mathbf{\%})\end{array}$ & $\begin{array}{l}\text { Abruption placenta } \\
(\mathbf{n = 2 9})(\%)\end{array}$ & P value \\
\hline LSCS & $67(97)$ & $15(51.7)$ & $<0.05=$ Significant \\
\hline PPH & $12(17.4)$ & $3(10.3)$ & $>0.05=$ not significant \\
\hline Couvelaire uterus & 0 & $5(17.27)$ & $<0.05=$ Significant \\
\hline Scar dehiscence & $2(2.9)$ & 0 & $>0.05=$ not significant \\
\hline Caesarean hysterectomy & $7(10.14)$ & 0 & $>0.05=$ not significant \\
\hline Sepsis & $1(1.45)$ & 0 & $>0.05=$ not significant \\
\hline ICU admission & $10(14.5)$ & $5(17.24)$ & $>0.05=$ not significant \\
\hline Maternal mortality & $2(2.9)$ & 0 & $>0.05=$ not significant \\
\hline Blood transfusion & $65(94.2)$ & $21(72.4)$ & $<0.05=$ significant \\
\hline
\end{tabular}

Table 8: Fetal outcome in placenta previa and abruption placenta.

\begin{tabular}{|llll|}
\hline Fetal outcome & $\begin{array}{l}\text { Placenta previa } \\
(\mathbf{n = 6 9 )}(\%)\end{array}$ & $\begin{array}{l}\text { Abruptio placenta } \\
(\mathbf{n = 2 9})(\%)\end{array}$ & P value \\
\hline Stillborn & $14(19.4)$ & $14(48.3)$ & $<0.05=$ Significant \\
\hline NICU admission & $35(48.6)$ & $14(48.3)$ & $>0.05=$ not significant \\
\hline Neonatal death & $15(20.8)$ & $5(17.2)$ & $>0.05=$ not significant \\
\hline Birth weight & & & $>0.05=$ not significant \\
\hline$<1 \mathrm{~kg}$ & $9(12.5)$ & $5(17.2)$ & $<0.05=$ significant \\
\hline $1-15 \mathrm{~kg}$ & $10(13.8)$ & $12(41.4)$ & $>0.05=$ significant \\
\hline $1.5-2.5 \mathrm{~kg}$ & $40(58)$ & $9(31)$ & \\
\hline$>2.5 \mathrm{~kg}$ & $10(13.8)$ & $3(10.3)$ & $>0.05=$ not significant \\
\hline Gestational age & & & $>0.05=$ not significant \\
\hline $28-34$ weeks & $26(37.7)$ & $13(44.8)$ & $>0.05=$ not significant \\
\hline $34-37$ weeks & $24(34.8)$ & $9(31)$ & \\
\hline$>37$ weeks & $19(27.5)$ & $7(24.1)$ &
\end{tabular}

\section{DISCUSSION}

In our study, out of 100 cases of APH $69 \%$ cases were of placenta previa followed by abruptio placenta in $29 \%$ cases and rest $2 \%$ cases were unclassified APH. Similar results were seen in study conducted by Yadav et al in 2019 which shows $76.8 \%$ cases were of placenta previa followed by $20.5 \%$ cases of abruptio placenta and rest $2.7 \%$ cases were unclassified. ${ }^{9}$

In our study $86 \%$ of the patients were below 30 years age, which was similar to the result reported by Sharma et al and Rajoriya et al in which the $72 \%$ and $51.2 \%$ cases of APH were belonged to aged 26-30 years. ${ }^{10,11}$ Similar results were reported by Das et al, Abbasi et al also reported the mean age 30 years. ${ }^{12,13}$ In this study we found that incidence of APH is more in multigravida cases $(86 \%)$ than in primigravida cases $(14 \%)$. Other studies Yadav et al and Majumdar et al have also reported high incidence of APH in multigravida which was about 5-8 times higher than primigravida.9,17 Maternal age is often cited as a risk factor for APH. Although a 15 year population based study in Norway shows a strong relationship between maternal age and abruption, other studies suggested that there is no increase risk for placental abruption among older women when parity and hypertensive diseases are excluded. It suggested that damaged endometrium, impaired decidualization, and aberrant vasculature due to increasing parity is responsible for APH, not increasing maternal age. $^{14}$

Majority of cases i.e 74\% of APH belonged to rural area and $26 \%$ cases belonged to urban area which is similar to the result found in study conducted by Maurya et al. ${ }^{15}$

Most of the cases of APH was seen among illiterate group which was $38 \%$ this result is in concordant with the study conducted by Addisu et al, it indicates that incidence of APH falls as literacy increases. ${ }^{16}$ Probably with education a woman has more control over her fertility decisions. 
Out of total 100 cases, $75 \%$ cases were of upper lower and lower group and $25 \%$ cases were belongs to upper middle and lower middle. Similar result was seen in study conducted by Maurya et al. ${ }^{15}$ It indicates that inci-dence is high in low SES group because of less awareness and perhaps less reach for family planning in this group.

In our study $70 \%$ cases of APH were reported in hospital with painless bleeding per vaginum, this result was similar to previous study conducted by Yadav et al which reports $64.8 \%$ cases were unbooked and presented with painless vaginal bleeding. ${ }^{9}$ Similar result was seen with study conducted by Maurya et al and Pandey et. ${ }^{15,17} 13 \%$ cases presented with painful bleeding, $15 \%$ cases presented with features of pre-eclampsia. $1 \%$ had history of convulsion and $1 \%$ had presented with PPROM.

Second major risk factor for APH in our study is previous history of LSCS (30\%). History of Previous uterine surgery is significantly seen in placenta previa. In present study 22 out of 69 cases of placenta previa i.e $32 \%$ cases had history of previous caesarean section. This is comparable to the study in Grant Medical College and Sir JJ Group of Hospitals and Medical college, Jodhpur, India and Iran which shown that the uterine scar of cesarean section prevented migration of the placenta during the course of pregnancy towards the more vascu-larized uterine fundus. ${ }^{20}$

In this study 15 out of 29 cases of abruption placenta i.e $51.72 \%$ of cases were associated with HDP suggesting it is one of major risk factor for abruption placenta. This result is similar to study conducted by Wasnik et al 2015 that shows $61 \%$ cases of Placenta Previa had history of caesarean section and $73 \%$ cases of abruption placenta were associated with pregnancy induced hypertension. ${ }^{21}$

In our study maternal morbidity and mortality is significantly higher in placenta previa cases compared to abruption placenta. The cesarean section rate in placenta previa group (97\%) is significantly higher as compared to abruptio placenta group which is similar to study done by Jharaik et al in which rate of cesarean section is $72 \%$ in placenta previa group and $25 \%$ in abruptio placenta group. $^{26}$ In this study, blood and blood products transfusion were more in placenta previa group compared to abruptio placenta group which is statistically significant. Similar result was reported study conducted by Wasnik et al and Rajoriya et al in which $75 \%$ and $86 \%$ of cases requires blood transfusion respectively.21,11

In this study, PPH is more in placenta previa group than abruption placenta group although we found it insignificant, similar result were found in study conducted by Yadav et al 2019. ${ }^{\circ}$ Crane et al also reported the incidence of PPH in APH to be $19 \% .^{22}$

Scar dehiscence, sepsis, hysterectomy, maternal mortality, these maternal complication were seen only in cases of placenta previa. In our study maternal mortality was $2.9 \%$ in placenta previa group which is higher than $2 \%$ in Takai et al, where the late referral and difficulties with transportation may be responsible for many maternal deaths. ${ }^{28}$

Antepartum hemorrhage has been implicated as major cause of perinatal death which is in agreement with other studies. This study confirmed the established finding that those with APH were more likely to have ad-verse neonatal outcome, such as low birth weight, NICU admission, preterm deliveries and stillbirths. ${ }^{28,29}$

Still birth was more in abruptio placenta group as compared to placenta previa group which is statistically significant. This result was similar to study conducted by Behran et al who also found stillbirth more in abruption placenta group (43\%) compared to placenta previa group $(33.3 \%)$. Both the studies demonstrated high stillbirth in abruption placenta as compared to placenta previa group. This was because most of the cases in abruption group presented late and already had complications at the time of admission, while in placenta previa group diagnosis was made early by ultrasound before they became symptomatic clinically, hence they were managed early and carefully. ${ }^{30,31}$

Neonatal death was more in placenta previa group compared to abruption placenta group although this result is statistically insignificant.

Very low birth weight babies were more in abruption placenta group while low birth weight babies were more in placenta previa group. This result is statistically significant. Similar result were found in study conducted by Kumar et al. ${ }^{31}$ This high incidence is due to more incidence of iatrogenic preterm delivery.

NICU admission and gestational age at the time of delivery were comparable in both the group. Perinatal mortality was high $45 \%$ which is similar to Yadav et al and Tyagi et al which shows $35 \%$ and $42 \%$ perinatal mortality respectively. ${ }^{9,19}$

In our study, we found the maternal outcome is poor in placenta previa group and the perinatal outcome is worse in abruptio placenta group. Further, studies on APH are needed to prove this results. The main limitation of this study is less number of cases.

\section{CONCLUSION}

APH neither can be reliably predicted nor can be prevented but only a comprehensive focused experienced team work can reduce maternal and perinatal morbidity and mortality. Women should be encouraged and helped to change modifiable risk factors like planned pregnancy. Placental causes are most common cause of APH. Out of placental causes Placenta previa is commonest. Most of the cases of APH is due to high incidence of caesarean section. Therefore, there should be regular caesarean audit for 
definite indication of caesarean section. We feel that maternal and perinatal morbidity and mortality could be reduced by early registration, regular antenatal care, improved nutritional status, better antenatal services, improved transportation and time-ly caesarean section. Good facilities for caesarean section, 24 hours availability of blood banks and good NICU facilities and multidisciplinary approach can improve maternal and perinatal outcome of APH.

\section{Funding: No funding sources}

Conflict of interest: None declared

Ethical approval: The study was approved by the Institutional Ethics Committee

\section{REFERENCES}

1. Mishra R. Ian Donald's practical obstetric problems.7th Ed. Lippincott Williams and Wilkins. 2014;315-28.

2. Miller DA. Treatment of antepartum haemorrhage.Women's and children's Hospital,Department of obstetrics and gynaecology, Los Angeles, USA.

3. Oyelese Y, Smulian JC. Placenta previa, placenta accreta and vasa previa. Obstet Gynecol. 2006;107(4):927.

4. Tikkanen M. Placental abruption: epidemiology, risk factors and consequences. Acta obstet Gynecol Scand. 2011:90(2):140-9.

5. Nagpurkar S, Tale A, Ranjwan B. Risk factors for for antepartum hemorrhage: a hospital based study. Int J Recent Trends Sci Technol. 20115;15(2):2277-812.

6. Nicholas N, Bhide A. Antepartum haemorrhage. Current Obst Gynaecol. 2006;16(2):79-83.

7. Dutta DC. Antepartum haemorrhage. In: Konar HL, editor. Textbook of obstetrics. 6th edition. Kolkata, India: New central book agency. 2006:243-6.

8. Harrison KA. Maternal mortality. Brt J Obstetrics Gynecol. 1985;5:100-15.

9. Yadav MC, Mehta K, Choudhary V. A study of Antepartum Hemorrhage and its maternal and perinatal outcome at tertiary care hospital in western Rajasthan. JMSCR. 2019;7(09):80-5.

10. Sharma N, Gupta M. Antepartum haemorrhage and its maternal and perinatal outcome at tertiary care hospital. Int $\mathbf{J}$ Health and Clinical research. 2021;4(3):272-6.

11. Rajoriya M. Int J Reprod Contracept Obstetrics Gynecol. 2020;9(11):4531-34.

12. Das B. Antepartum hemorrhage in three decades. J Obstetrics Gynaecol India.1987;25:636-7.

13. Abbasi RM, Rizwan N, Farooq S. Fetomaternal outcome among abruptio placenta cases at a university hospital of Sindh. J Liaquat Uni Med Health SCI. 2008;7(2):106-9.

14. Gabbe SG, Niebyl JR. Obstetrics Normal and Problem pregnancies. First South Asia Edison. 397.
15. Maurya A, Arya S. Study of Antepartum haemorrhage and its Maternal and perinatal outcome. Int J SCI Res Publ. 2014.

16. Assefa A, Fantahun Y, Mesfin E. Maternal and Perinatal Outcome of antepartum hemorrhage. Ethiopian Journal of Reproductive Health. 2020;12.

17. Pandey VP, Pandey M. Study of Antepartum haemorrhage and its maternal and perinatal outcome. 2016. Available at: http:I sear.li.mahidol.ac.th/handle/ 123456789/175784. Accessed on 10 July 2021.

18. Majumder S, Shah PT, Deliwala KJ, Patel RV, Madhiya A. Study of fetomaternal outcome of antepartum hemorrhage in pregnancy. IJRCOG. 2015;4(6):1936-39.

19. Tyagi P, Yadav N, Sinha P, Gupta U. Study of Antepartum haemorrhage and its maternal and perinatal outcome. Int J Reprod Contracept Obstet Gynaecol. 2016;5:3972-7.

20. Edosa, Mohammedamin H, Gelawdwos G. Risk factors of Antepartum Hemorrhage among mothers who gave birth at Suhul general hospital, 2016: A case control study. J Multydiscip Healthc. 2021;14:271-8.

21. Wasnik SK, Naiknaware SV. Antepartum Hemorrhage: Cause \& Its Effects on Mother and child: An evaluation. Obstet Gynecol Int J. 2015;3(1):00072.

22. Crane JM, Van den Hof MG, Dodds L. Neonatal outcome with placenta Previa. Obstet Gynaecol. 1999;93(4):541-4.

23. Arora R, Devi U, Majumdar R. Perinatal morbidity and mortality in Antepartum Hemorrhage. J Obstet Gynaecol India. 2001;51(30):102-4.

24. Samal SK, Rathore S, Rani R, Ghose S. Maternal and perinatal outcomes in cases of Antepartum haemorrhage : a 3 year observational study in a tertiary care hospital. Int J Reprod Contracept Obstet Gynaecol. 2017;6:1025-9.

25. Jain S, Jain N, Dahiya P, Rohilla S, Malik R, Jain S et al. Int J Reprod Contracept Obstet Gynecol. A prospective study of maternal outcome in antepartum hemorrhage in tertiary care center in northern India. 2016;5(1).

26. Jharaik H, Sharma A, Sharma R, Sharma K. Comparison of placenta previa and abruptio placenta and its maternal and perinatal outcome. International journal of clinical obstetrics and gynaecol. 2019;3(4):161-6.

27. Singhal S, Nymphaea, Nanda S. Maternal and perinatal outcome in Antepartum Hemorrhage: A study at a Tertiary Care referral Institute. The internet journal of gynaecology and obstetrics. 2007;9:1-4.

28. Takai IU, Sayyadi BM, Galadanci HS. Antepartum hemorrhage: a retrospective analysis from a northern Nigerian teaching hospital.

29. Adekanle A, Adeyemi A, Fadero F. Antepartum haemorrhagein LAUTECH teaching hospital south western Nigeria. J Med Sci. 2011;2:1243-7.

30. Behran Y. Predictors of perinatal mortality associated with placenta previa and placental abruption: an 
experience from a low income country. Journal of Pregnancy. 2014;307043.

31. Kumar N, Jourwal S, Rawat RP. Third trimester bleeding: it's effect on foetal outcome -a study at tertiary care hospital. JMSCR. 2020;08(06):288-93.
Cite this article as: Singh R, Aditya V, Agarwal S, Maurya G, Kumari A, Sharma NR. Identifying the risk factors of antepartum haemorrhage and to evaluate the feto maternal outcome in antepartum haemorrhage cases. Int J Reprod Contracept Obstet Gynecol 2021;10:3786-92. 